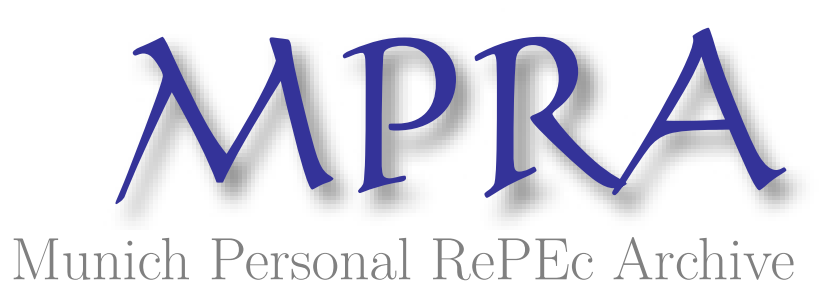

\title{
The Dynamic Effects of Changes to Japanese Immigration Policy
}

Phillips, Kerk L.

Brigham Young University

July 2010

Online at https://mpra.ub.uni-muenchen.de/23673/

MPRA Paper No. 23673, posted 07 Jul 2010 09:01 UTC 


\title{
The Dynamic Effects of Changes to Japanese Immigration Policy
}

\author{
Kerk L. Phillips* \\ Department of Economics \\ P.O. Box 22363 \\ Brigham Young University \\ Provo, UT 84602-2363 \\ phone: (801) 422-5928 \\ fax: (801) 422-0194 \\ email: kerk_phillips@byu.edu
}

July 2010

keywords: labor migration, factor mobility, dynamic general equilibrium, Japan JEL codes: F15, F22, F42

* Research assistance was provided by Chad Lee, Adam Owens, Ryan Decker, Li Jialin and funded by the David M. Kennedy Center for International Studies at Brigham Young University. 


\begin{abstract}
This paper constructs a multi-sector dynamic general equilibrium model for a trading economy. We incorporate three major factors of production: capital, skilled labor \& unskilled labor. We solve and calibrate the model using data from Japan. We then consider changes to immigration policy. We are able to examine the effects on output, consumption, wages, and utility. We do this for both the new steady state and for the time-path leading to that steady state. In addition, we are able, if we so wish, to impose a series of unrelated macroeconomic shock to the model. This has the advantage of allowing us to calculate confidence bands around our policy impulse response functions.

We find that allowing skilled labor to immigrate leads to greater welfare gains in the steady state. We also show that there is a great deal of uncertainty surrounding the exact time path to a new steady state in the presence of the typical fluctuations associated with business cycles. We find a great deal of inertia in the transition to a new steady state.
\end{abstract}




\section{Introduction and Literature Review}

Immigration issues are among the most political sensitive economic issues confronted by policy makers. Whether or not to allow workers from low wage countries to migrate to high wage countries is a source of constant political debate in high wage countries. Western Europeans struggle with the optimal number of workers from Eastern Europe, North Africa and the Middle East. Americans confront issues of immigration from Mexico and other parts of Latin America, as well as from China and other countries in Asia.

Due to its isolation and very strict immigration laws, Japan has not struggled with immigration as much as other developed countries. As incomes have risen, the lure of higher wages has made Japan a more attractive place to work. Japanese firms find the lower wages that immigration would induce attractive. Japanese workers find this correspondingly unattractive.

In this paper we examine the effects of various broad changes to immigration policy in Japan. We build and calibrate a multi-sector dynamic stochastic general equilibrium (DSGE) model and consider changes in the supply of both unskilled and various types of skilled labor. We are interested in the effects these policy changes will induce on the wages of existing domestic workers and on the aggregate effects on output, consumption and other key measures of economic activity.

This paper is not the first to examine these issues in this way. Goto (1998) builds and calibrates a small open computable general equilibrium (CGE) model for Japan. He groups goods into three categories: exportables, importables, and nontraded. Rather than aggregating into a single final good, he allows each of these to enter the utility function separately. Since the model is not explicitly dynamic, he holds capital in each production sector constant. Labor, however, is homogenous and mobile across sectors. Goto examines the effects of several shocks having to do with changes in trade and international prices. His most interesting result, however, is that small amounts of labor immigration reduce welfare, while sufficiently large amounts may actually improve welfare.

Choi (2004) builds a static general equilibrium model of the South Korean economy. His model is similar in spirit to ours, but has important differences in the modeling. He allows for imperfect competition in intermediate goods which are produced using capital and skilled labor specific to the particular intermediate good. Final goods are perfectly competitive and produced with capital and unskilled labor. Choi focuses on the welfare effects of easing immigration 
restrictions and is concerned primarily with behavior in the short run as a result of business cycle movements. He reports the effects of various business cycle shocks to the economy on welfare and wage inequality.

In contrast, this paper is explicitly dynamic and uses the tools of DSGE modeling. We focus on the long-run transition to a new steady state equilibrium. Business cycle movements are important only because they add uncertainty and volatility to this transition. By incorporating these shocks, however, we are able to present not only impulse responses of key variables to immigration shocks, but also derive confidence bands about these responses.

Section 2 below presents the theoretic model. Section 3 shows how the model can be rendered stationary and suitable for finding a steady state. We also show how this steady state is found. In section 4 we discuss calibration of the model. We also present and discuss the steady state of a baseline calibration. Section 5 discusses possible policy changes to immigration and introduces the stylized policy changes we will simulate. In each of these cases we consider immigration policies that bring the foreign population to levels similar to those found in Germany and the U.S. Our policies differ in the mix of skilled and unskilled workers that are allowed to immigrate. Section 6 explains the technique for finding linear approximations of the policy functions that govern the dynamics of our simulated model. In section 7 we simulate the various cases from section 5 for simple one-time changes in policy for an economy with no other source of macroeconomic shocks. We are able to derive smooth transition paths from the initial steady state to the new one associated with the higher number of workers. Section 8 repeats these simulations while simultaneously allowing for macroeconomic shocks to technology and consumer confidence. By performing a large number of simulations for each case we are able to derive confidence bands for the key variables considered. Section 7 concludes the paper.

\section{A Dynamic General Equilibrium Model}

We construct a small open economy multi-sector dynamic general equilibrium model. Our model allows for a single non-traded final good $(Y)$ which is used for both consumption $(C)$ $\&$ investment in capital goods. The final good is produced using five intermediate goods via an Armington aggregator. The intermediate goods $\left(Y_{i}\right)$ can be traded internationally or may be nontraded depending on the nature of the good. They are produced using capital $(K) \&$ two types of 
labor. The two types of labor are skilled and unskilled $(N)$. Each intermediate good uses a unique type of skilled labor $\left(L_{i}\right)$ which is therefore a specific factor. Unskilled labor can be used to produce any of the intermediate goods. All types of labor are supplied in fixed endowments. Capital is non-traded and accumulates optimally over time. Productivity $\left(z_{A}\right)$ is exogenous and has both a trend and stochastic component. There is also a consumer confidence shock $\left(z_{R}\right)$ which we model explicitly below which alters the household's perceived optimal time path for consumption and savings. Households may not save or borrow internationally and trade balances every period.

Each period households maximize utility from consumption. They supply capital and various forms of labor inelastically and save by holding physical capital. The typical consumer's problem is illustrated by the Bellman equation in (2.1) which is maximized subject to the budget constraint in (2.2).

$$
\begin{aligned}
& V(K ; \Theta)=\operatorname{Max}_{K^{\prime}} U(C)+\beta \mathrm{E}\left\{e^{z_{R}} V\left(K^{\prime} ; \Theta^{\prime}\right)\right\} \\
& C=\sum_{i} w_{i} \bar{L}_{i}+v \bar{N}+(1+r-\delta) K-K^{\prime}
\end{aligned}
$$

In these equations, $w_{i}$ is the wage rate for skilled labor of type $i, v$ is the wage for unskilled labor, $r$ is the real rental rate for domestic capital, $\delta$ is the depreciation rate of capital, $C$ is real consumption, $K$ is holdings of real domestic capital, and $\Theta$ is the exogenous information set (prices, shocks, etc.).

The first-order conditions from this maximization problem reduce to the Euler equation in $(2.3)$.

$$
U_{C}=\beta \mathrm{E}\left\{e^{z_{R}} U_{C}^{\prime}\left(1+r^{\prime}-\delta\right)\right\}
$$

With the assumption of a constant elasticity of substitution utility function this becomes equation (2.4).

$$
C^{-\sigma}=\beta \mathrm{E}\left\{e^{z_{R}{ }^{\prime}} C^{\prime-\sigma}\left(1+r^{\prime}-\delta\right)\right\}
$$

Final goods producers maximize profits from purchasing all five intermediate goods and producing the final output good, as shown in equation (2.5). The production function is an Armington aggregator and yields constant expenditure shares for each intermediate good in final production. 
$\operatorname{Max}_{\left\{F_{i}\right\}} \Pi_{F}=\prod_{i} F_{i}^{a_{i}}-\sum p_{i} F_{i} ; \sum_{i} a_{i}=1$

Here, $F_{i}$ is the quantity of intermediate good used and $p_{i}$ is its real price.

The first-order conditions reduce to equations (2.6) and (2.7).

$$
\begin{aligned}
& p_{i} F_{i}=a_{i} Y \\
& Y \equiv \prod_{i} F_{i}^{a_{i}}
\end{aligned}
$$

Intermediate goods producers maximize profits from hiring capital and labor and selling a particular intermediate good as in equation (2.8).

$$
\operatorname{Max}_{K_{i}, L_{i}} \Pi_{i}=p_{i} K_{i}^{b_{i}}\left(e^{g t+z_{A}} N_{i}\right)^{c_{i}}\left(e^{g t+z_{A}} L_{i}\right)^{1-b_{i}-c_{i}}-r_{i} K_{i}-w_{i} L_{i}-v_{i} N_{i}
$$

Here, $N_{i}$ is the unskilled labor demanded in sector $i, L_{i}$ is the skilled labor demanded in sector $i$, and $z_{A}$ is a technology shock. The first-order conditions reduce to equations (2.9) (2.12).

$$
\begin{aligned}
& r_{i} K_{i}=b_{i} p_{i} Y_{i} \\
& v_{i} N_{i}=c_{i} p_{i} Y_{i} \\
& w_{i} L_{i}=\left(1-b_{i}-c_{i}\right) p_{i} Y_{i} \\
& Y_{i} \equiv K_{i}^{b_{i}}\left(e^{g t+z_{A}} N_{i}\right)^{c_{i}}\left(e^{g t+z_{A}} L_{i}\right)^{1-b_{i}-c_{i}}
\end{aligned}
$$

All markets must clear and this clearing imposes additional restrictions on the model. Labor is not traded internationally, but some intermediate goods are. We allow exports for all intermediate goods and impose any relevant trade restrictions later in our simulations.

Clearing of the final goods market gives (2.13).

$$
Y+(1-\delta) K=C+K^{\prime}
$$

Clearing in the factor markets gives equation (2.14) - (2.16).

$$
\begin{aligned}
& K=\sum_{i} K_{i} \\
& \bar{N}=\sum_{i} N_{i} \\
& \bar{L}_{i}=L_{i}
\end{aligned}
$$


International trade in intermediate goods gives equation (2.17).

$Y_{i}=F_{i}+X_{i} \forall i$

Here, $X_{i}$ is exports of good $i$.

Balanced trade gives (2.18).

$\sum_{i \in \text { traded }} p_{i} X_{i}=0$

By Walras Law one of the equations in $(2.13)-(2.18)$ is redundant. We choose to omit (2.18).

Mobility of capital and unskilled labor across sectors implies these factor prices must be identical across industries as in equations (2.19) and (2.20).

$$
\begin{aligned}
& r_{i}=r \forall i \\
& v_{i}=v \forall i
\end{aligned}
$$

Traded goods are linked to foreign prices by (2.21a). This equation omits any tariffs, but this omission is unimportant since we use this only to calibrate the model and establish international prices consistent with observed trade patterns. We interpret these prices as being net of tariffs.

$$
p_{k}=q p_{k}^{*} ; k \in \text { traded }
$$

If goods are not traded then we replace equation (2.21a) with (2.21b) for that industry.

$$
x_{j}=0 ; j \in \text { nontraded }
$$

Finally, equations (2.22) and (2.23) specify the laws of motion for the two exogenous shock processes.

$$
\begin{aligned}
& z_{A}{ }^{\prime}=\rho_{A} z_{A}+e_{A}{ }^{\prime} ; e_{A}{ }^{\prime} \sim \operatorname{iid}\left(0, \sigma_{A}^{2}\right) \\
& z_{R}{ }^{\prime}=\rho_{R} z_{R}+e_{R}{ }^{\prime} ; e_{A}{ }^{\prime} \sim \operatorname{iid}\left(0, \sigma_{R}^{2}\right)
\end{aligned}
$$

\section{Stationarizing and the Model's Steady State Solution}

Equations (2.2), (2.4), (2.6), (2.7), (2.9) - (2.17) and (2.19) - (2.23) are a system of eighteen dynamic equations that define the system. 
We can reduce the dimensionality of the system by using (2.17) to substitute for the values of the $F_{i}$ 's. We also define allocations of capital and unskilled labor over each of the $I$ industries as shares of the totals and denote these shares as $\left\{\phi_{i}^{K}, \phi_{i}^{N}\right\}$. These replace the variables $K_{i}$ and $N_{i}$. Finally we define the export share in an intermediate industry as $x_{i} \equiv X_{i} / Y_{i}$ and replace the $X_{i}$ 's.

As specified, the system generates data that are non-stationary and our solution technique requires linear approximations of these equations about a steady state. Therefore, it is necessary to redefine variables in a way that renders the model stationary.

Equation (2.12) shows that technology is growing with a trend growth rate of $g$. Hence we can transform all growing variables $\left(K,\left\{v_{i}, w_{i}, Y_{i}\right\}_{i=1}^{I}, Y, C\right)$ by dividing them by $e^{g t}$. We denote transformed variables by placing a carat over them.

This transformed system of equations is given by (3.1) - (3.16)

$$
\begin{aligned}
& z_{A}{ }^{\prime}=\rho_{A} z_{A}+e_{A}{ }^{\prime} ; e_{A}{ }^{\prime} \sim \operatorname{iid}\left(0, \sigma_{A}^{2}\right) \\
& z_{R}{ }^{\prime}=\rho_{R} z_{R}+e_{R}{ }^{\prime} ; e_{A}{ }^{\prime} \sim \operatorname{iid}\left(0, \sigma_{R}^{2}\right) \\
& 1=\beta \mathrm{E}\left\{e^{z_{R}{ }^{\prime}}\left(\frac{\hat{C}^{\prime}(1+g)}{\hat{C}}\right)^{-\sigma}\left(1+r^{\prime}-\delta\right)\right\} \\
& p_{i} \hat{Y}_{i}\left(1-x_{i}\right)=a_{i} \hat{Y} \\
& r_{i} \phi_{i}^{K} \hat{K}=b_{i} p_{i} \hat{Y}_{i} \\
& \hat{v}_{i} \phi_{i}^{N} \bar{N}=c_{i} p_{i} \hat{Y}_{i} \\
& \hat{w}_{i} \bar{L}_{i}=\left(1-b_{i}-c_{i}\right) p_{i} \hat{Y}_{i} \\
& \hat{Y}_{i}=\left(\phi_{i}^{K} \hat{K}\right)^{b_{i}}\left(e^{z_{A}} \phi_{i}^{N} \bar{N}\right)^{c_{i}}\left(e^{z_{A}} \bar{L}_{i}\right)^{1-b_{i}-c_{i}} \\
& 1=\sum_{i} \phi_{i}^{K} \\
& 1=\sum_{i} \phi_{i}^{N} \\
& \hat{C}=\hat{Y}+(1-\delta) \hat{K}-(1+g) \hat{K}^{\prime} \\
& r_{i}=r \\
& \hat{v}_{i}=\hat{v} \\
& \hat{v} \\
& 1
\end{aligned}
$$




$$
\begin{aligned}
& \hat{Y}=\sum_{i} p_{i} \hat{Y}_{i} \\
& \prod_{i}\left(\frac{a_{i}}{p_{i}}\right)^{a_{i}}=1 \\
& x_{j}=0 ; j \in \text { nontraded } \\
& p_{k}=q p_{k}^{*} ; k \in \text { traded }
\end{aligned}
$$

Equations (3.1) - (3.16) are a system of dynamic equations which can be calibrated to produce a desired steady state. The steady state solution can be found by replacing the values of all the variables in this system with their steady state values. Equations (3.9) - (3.16) can be used as definitions. Equations (3.1) and (3.2) imply the steady state values of the shocks are zero. This reduces the system to (3.3) - (3.8); a system of fifteen equations in fifteen unknowns, $\bar{K}, \bar{q},\left\{\bar{x}_{j}\right\}_{j \in t r a d e d},\left\{\bar{p}_{k}\right\}_{k \in \text { nontraded }},\left\{\bar{\phi}_{i}^{K}, \bar{\phi}_{i}^{N}\right\}_{i=1}^{I-1}$. This system might possibly be solved algebraically, but we choose to solve it numerically instead.

\section{Baseline Calibration and Description of the Steady State}

We have the following set of parameters for which we need numerical values if we are to solve and simulate our model. The set is $\beta, \delta, \sigma, g,\left\{a_{i}, b_{i}, c_{i}, \overline{L_{i}}\right\}, \bar{N}, p_{k \in t r a d e d}^{*}$.

$\delta$ is the depreciation rate and is set to $6.11 \%$, the average of the observed ratio of depreciation reported by the IMF to a capital stock measure constructed by the perpetual inventory method from IMF real investment data. We use the period $1955-2003$.

$g$ is the annual growth rate of technology, which we set $.512 \%$, the average value of the Solow residual for $1986-2003$.

$g, \beta$ (the subjective discount factor) and $\sigma$ (the intertemporal elasticity of substitution) are linked via the steady state version of equation (3.3), $1=\beta(1+g)^{-\sigma}(1+\bar{r}-\delta)$. We set $\sigma$ to 1 and choose a value for $\beta$ of .986 , which implies an annual real net return on capital equal to the ex post annual real return on government bonds between 1966 and 2008 of $1.876 \%$.

The values for the sector shares in GDP (the $a_{i}$ 's) come from the GTAP6 database. We rely on the publicly available summaries of the database which aggregate industries into ten broad categories. We further aggregate these into five groups: agriculture, extraction, manufacturing, traded services, and non-traded services. We define the agriculture industry as 
any of the GTAP industries that use land as a factor of production. Similarly, extraction is any industry that uses natural resources. For these two industries only we modify our production function in equation (3.8) to include a fourth factor, which we interpret as either land or natural resources.

$$
\hat{Y}_{i}=\left(\phi_{i}^{K} \hat{K}\right)^{b_{i}}\left(e^{z_{A}} \phi_{i}^{N} \bar{N}\right)^{c_{i}}\left(e^{z_{A}} \bar{T}\right)^{d_{i}}\left(e^{z_{A}} \bar{L}_{i}\right)^{1-b_{i}-c_{i}-d_{i}}
$$

We set the stock of land $(\bar{T})$ and natural resources $(\bar{R})$ both to 100 via normalization of units.

To obtain numerical values for the $a_{i}$ 's we take the ratio of total value-added on goods in that sector to total value-added on all goods.

We also calculate the $b_{i}$ 's, $c_{i}$ 's and $d_{i}$ 's, by taking the total compensation reported for each factor in that industry as a percentage of the value-added on the good.

For labor endowments we set the total endowment of labor to 100 by normalization. We obtain the relative amounts of unskilled labor and skilled labor by using data from the International Labor Organization and matching these to our five sectors as closely as possible.

To obtain international prices we use export shared for each of our industries as calculated from the GTAP data. We then solve for the steady state of our model using international prices as variables and export shares as long-run steady state values. When simulating our model we treat the prices of traded goods that we find this way as fixed parameters. The values of all parameters are reported for in table 1.

To determine which industries can be best classified as non-traded we sum the value of exports and imports and divide by value-added for that industry. If this number is less than 5\% we classify then industry as non-traded. By this criterion only one industry, non-traded services, is not a tradable good.

\section{Steady States of Various Policy Options}

We consider relaxation of immigration constraints by imagining a policy that allows the labor endowment of the economy to rise by some fixed percent. We view foreign and domestic labor as perfect substitutes as long as the labor is of the same type. A policy maker can choose to relax or constrain immigration in general which would alter the supplies of all labor. Or the policy maker could target particular types of labor, and leave endowments of the other types unchanged. 
As figure 1 shows, the percentage of foreign residents to the total population is quite low in Japan compared to other developed countries. This number was $1.63 \%$ in 2006 . By contrast, they were $11.71 \%$ for the United States in 2003 and $8.81 \%$ for Germany in 2006. We consider a change in immigration policy that raises the percentages from their current values to $9.50 \%$. (Roughly the average of the US and Germany over the past 20 years.)

The policies we consider differ in the types of labor allowed to immigrate.

1) We first consider a case where only unskilled labor is allowed to immigrate. This leads to an increase in the unskilled labor force of $11.15 \%$.

2) Secondly, we consider a case where both skilled and unskilled labor are allowed to immigrate in the same proportions of the current labor force. This leads to an increase in all types of labor of $9.14 \%$.

3) Third, we consider a case where both types of labor can immigrate, but skilled labor is given a priority. We allow equal numbers of workers of both types to enter the country, but since there are more unskilled workers in the workforce already, this leads to smaller percentage increases for unskilled labor. Unskilled labor rises by $5.57 \%$ and skilled labor rises by $25.44 \%$.

4) A fourth scenario is to allow only skilled labor into a country. In this case, we increase all stocks of skilled labor by $50.88 \%$.

5) For a fifth case we consider allowing skilled labor from only the non-traded services sector to immigrate. Thi is the sector that employs the most skilled labor and this leads to an increase of $L_{5}$ by $86.03 \%$.

6) Finally, we allow skilled labor from only the traded services sector (the second largest employer of skilled labor) to immigrate. This causes an increase in $L_{4}$ of $424 \%$.

The steady state values for the baseline case and for the six different immigration cases are presented in table 3. Several interesting patterns emerge from these tables. First, increases in skilled immigration lead to greater increases in capital, output and consumption than increases in unskilled immigration. The ranking in terms of output increases from lowest to highest is: 1) unskilled only, 2) proportional, 3) equal, and 4) skilled only. This ordering corresponds to greater proportions of skilled labor new immigration. Second, the highest gains in output and consumption come from targeting skilled labor in the traded services sector. Third, as the mix of immigration moves from unskilled to skilled labor, skilled wages fall and unskilled wages rise. 
Fourth, not surprisingly, increases in immigration specific types of skilled labor lead to a drop in the wages of that labor. Fifth, an increase in nontraded services labor causes the wages of all other types of labor to rise, while an increase in traded services labor causes wages in agriculture, extraction, and manufacturing to fall.

All these results are for the steady state, to which the economy will trend in the long. However, the long-run can be very far in the future and policy makers may well be interested in changes in output, consumption and wages along the transition path to this new steady state.

We now turn to these transition paths.

\section{Solving for the Model's Dynamics}

We use the method of undetermined coefficients to find linear approximations to the transition functions for the endogenous state variables in our model. Christiano (2002) and Uhlig (1999) discuss this method in detail.

We define four sets of variables from the system in equations (3.1) - (3.16). First are the exogenous state variables. We assign these to a vector $\mathbf{Z}_{t}$ as shown in (5.1).

$$
\mathbf{Z}_{t} \equiv\left[\begin{array}{ll}
z_{A} & z_{R}
\end{array}\right]
$$

Similarly, we put the log deviations of the endogenous state variables from their steady state values into a vector $\mathbf{X}_{t}$. We denote $\log$ deviations of variable with a tilde. There is only one of these, and we alter the timing so that capital chosen for production next period is part of vector $\mathbf{X}$ now.

$$
\mathbf{X}_{t} \equiv\left[\tilde{K}^{\prime}\right]
$$

We also define a set of endogenous non-state variables that cannot be easily solved as functions of the state variables. Uhlig (1999) refers to these as "jump" variables. We put these $\log$-deviations into a vector $\mathbf{Y}_{t}$.

$$
\mathbf{Y}_{t} \equiv\left[\begin{array}{llllllllllllll}
\tilde{q} & \tilde{p}_{1} & \hat{p}_{2} & \tilde{p}_{3} & \tilde{p}_{4} & \hat{p}_{5} & \tilde{\phi}_{1}^{K} & \tilde{\phi}_{2}^{K} & \tilde{\phi}_{3}^{K} & \tilde{\phi}_{4}^{K} & \tilde{\phi}_{1}^{N} & \tilde{\phi}_{2}^{N} & \tilde{\phi}_{3}^{N} & \tilde{\phi}_{4}^{N}
\end{array}\right]
$$

Lastly, we solve equations (3.4) - (3.11) \& (3.14) to define a set of definition variables that are functions of the vectors $\mathbf{X}_{t-1}, \mathbf{X}_{t}, \mathbf{X}_{t+1}, \mathbf{Y}_{t}, \mathbf{Y}_{t+1}, \mathbf{Z}_{t} \& \mathbf{Z}_{t+1}$.

Using these definitions we can construct linear approximations of equations (3.12), (3.13), (3.15) \& (3.16) of the form shown in equation (5.4).

$$
\mathbf{A} \mathbf{X}_{t}+\mathbf{B} \mathbf{X}_{t-1}+\mathbf{C} \mathbf{Y}_{t}+\mathbf{D Z} \mathbf{Z}_{t}=0
$$


Similarly, an approximation of (3.3) yields equation (5.5).

$\mathbf{F} \mathbf{X}_{t+1}+\mathbf{G} \mathbf{X}_{t}+\mathbf{H} \mathbf{X}_{t-1}+\mathbf{J} \mathbf{Y}_{t+1}+\mathbf{K} \mathbf{Y}_{t}+\mathbf{L} \mathbf{Z}_{t+1}+\mathbf{M Z} \mathbf{Z}_{t}=0$

Lastly, equations (3.1) \& (3.2) can be written as equation (5.6).

$\mathbf{Z}_{t+1}=\mathbf{N Z}_{t}+\boldsymbol{\varepsilon}_{t+1} ; \boldsymbol{\varepsilon}_{t+1} \sim \operatorname{iid}(\mathbf{0}, \boldsymbol{\Sigma})$

The derivative matrices in equations (5.4) and (5.5) can be found algebraically, or they can be found using numerical methods.

Both Christiano (2002) and Uhlig (1999) show how this system can be solved for linear transition functions for the endogenous state variables and jump variables as expressed in (5.7) \& (5.8).

$$
\begin{aligned}
& \mathbf{X}_{t}=\mathbf{P} \mathbf{X}_{t-1}+\mathbf{Q Z} \mathbf{Z}_{t} \\
& \mathbf{Y}_{t}=\mathbf{R} \mathbf{X}_{t-1}+\mathbf{S Z} \mathbf{Z}_{t}
\end{aligned}
$$

Given starting values for $\mathbf{X}_{0}$ and $\mathbf{Y}_{0}$, these two equations can be used in conjunction with (5.6) and a random number generator to simulate a series of deviations of variables from their

steady state values over any arbitrarily long history. Once these deviations are known for every period we can recover the stationary values for each period using equation (5.9)

$$
\hat{x}_{t}=\bar{x} e^{\tilde{x}_{t}}
$$

Finally, we can construct non-stationary time-series for these variables by adding back the growth component that was removed in section 3 .

$$
x_{t}=\hat{x}_{t} e^{g t}
$$

\section{Non-Stochastic Simulations of Transition Paths}

We examine the transition of our model economy from the current steady state to a new one by using the simulation methodology discussed in section 5. We set all exogenous shocks to zero to focus on the endogenous dynamics. We assume our economy is initially in the steady state, meaning that $\mathbf{X}_{t}=0$. This will cause the economy to remain in the steady state until something changes. When policy is changed in period $T$, the economy will have a new steady. We set the value of $\mathbf{X}_{t}$ in this period to $\mathbf{X}_{T}=\bar{K}_{\text {old }} / \bar{K}_{\text {new }}$. From this point in time on, the 
economy will slowly converge to the new steady state, its dynamics driven by the $\mathbf{P}$ matrix in equation (5.7).

Figure 3 shows a typical transition. In this case it is for an increase of skilled immigration only. Notice that in addition to the long-run changes in steady state values, these transition paths show immediate effects. For example, the increase in skilled labor (which is assumed to happen immediately) causes immediate increases in output of all intermediate and final goods, as well as consumption. It also has immediate effects on exports and factor prices. After these immediate effects, the economy slowly transitions to a new steady state as the capital stock adjusts slowly over time. In some cases the upward jump is followed by additional increases over time; as in the case of outputs and consumption. In other cases, however, the initial jump overshoots the new steady state value and the variable returns partway (exports and skilled wages) or all the way back (the interest rate) to the original value.

We report only this one example because we are interested in augmenting these transition paths with confidence bands.

\section{Monte Carlo Simulations of Transition Paths}

Transition paths like those from the preceding section can be misleading because they show the effects of a change in steady state while assuming there are no exogenous shocks. Since the shocks are, on average, zero this is an unbiased prediction. It gives no sense of the amount of variation from this average one should expect, however. It is useful to have some sort of confidence band around these average predictions.

To do this we conduct a series of Monte Carlo simulations. We proceed as described in section 7, but generate non-zero series for $\boldsymbol{\varepsilon}_{t}$ using a random number generator. In our case we assume that the two elements of $\boldsymbol{\varepsilon}_{t}$ are distributed as normally and independently from each other. The variance of each series is chosen to generate volatility of output that matches time-series data on real GDP from the country in question. For each case we run 1000 Monte Carlo simulations and report the upper and lower 95\% confidence bands for each time horizon from this set of simulations. We also report standard error bands by adding and subtracting two standard deviations at each time horizon. Both methods yield almost identical results. 
Figure 4 examines the same case as figure 3 . The difference is that we have added the deterministic trend back to all growing series and report the confidence and standard error bands. These graphs are the type of predictions a researchers would ideally provide to policy maker. That is, an average forecast of the likely effects of immigration reform, along with some feel for the uncertainty associated with these forecasts.

Figures 4-9 report transition paths under each of the six immigration policies discussed in section 5. These figures confirm many of the steady state results discussed in section 6 . However, there are some additional findings worth mentioning.

First, there is a great deal of uncertainty surrounding the time paths of almost all the time series. Only export shares show changes that are significantly different from the previous steady state over the 40 years shown.

Second, for stationary time series, like export shares \& the interest rate, the immediate adjustments to larger workforces are often much larger than the gradual adjustments to the new steady state that follow. For non-stationary series, the short-run jumps are much smaller in percentage terms because of the effects of long-run growth.

Third, regardless of the variable there is a great deal of inertia in the transition to the new steady state. Interest rates, for example, take more than twenty years to return close to their initial levels.

\section{Conclusions}

This paper has examined the effects of immigration liberalization in Japan \& Korea. Both these countries have foreign populations that are quite small compared to economies of similar size and level of development. We have calibrated a DSGE model of a trading economy and considered the effects of six different policies which bring the percentage of the population that is foreign to roughly the same levels as are observed in Germany or the US. Because we have modeled growing economies, the immediate effects of increased immigration are relatively small compared to long-run increases due to economic growth. Effects on exports are much more dramatic in the short run. We have shown that immigration reforms which targets skilled workers leads to greater welfare gains than those which allow in more unskilled labor. 


\section{Table 1}

\section{Parameter Values}

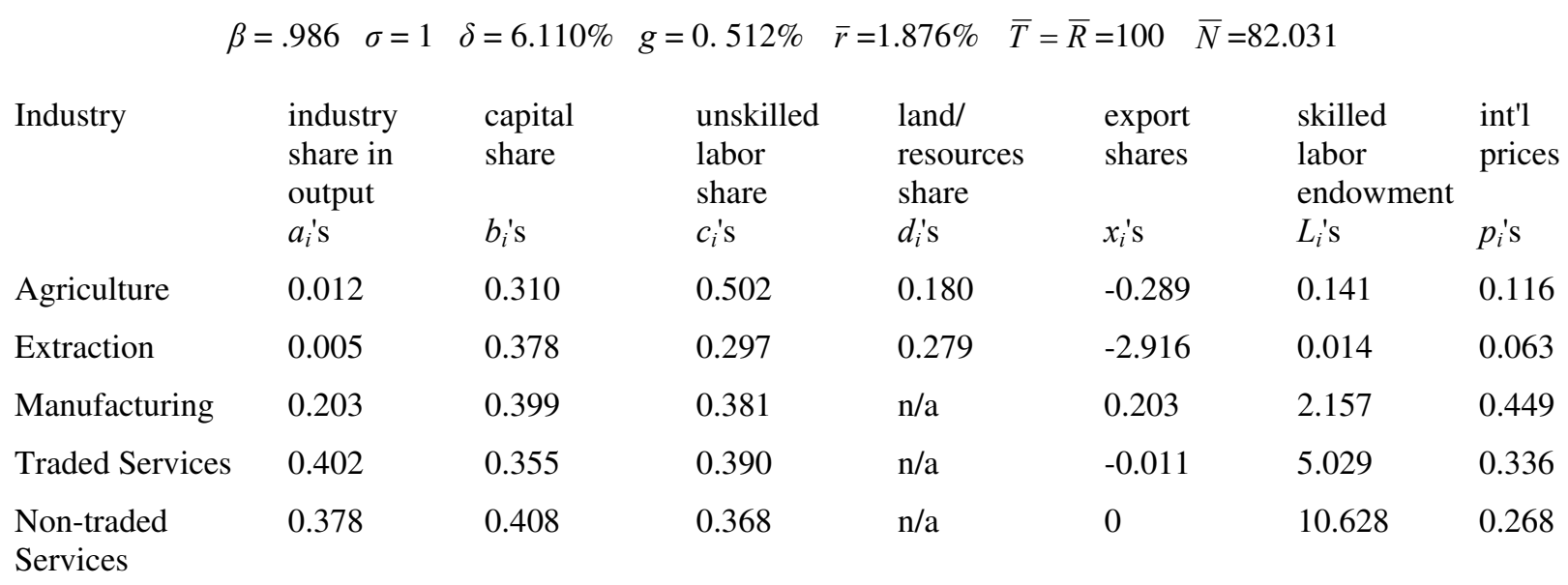


Table 2

Sensitivity Analysis of Baseline Parameters 


\section{Table 3}

\section{Steady State Values}

\begin{tabular}{|c|c|c|c|c|c|c|c|}
\hline \multirow[b]{3}{*}{$U$} & \multirow{2}{*}{\multicolumn{2}{|c|}{$\begin{array}{l}\text { Unskilled } \\
\text { Only }\end{array}$}} & \multicolumn{5}{|c|}{ Skilled } \\
\hline & & & Proportional & Equal & Only & L5 only & L4 only \\
\hline & 157.214 & 160.044 & 163.441 & 168.736 & 175.495 & 168.253 & 184.345 \\
\hline$K$ & 62.151 & 64.657 & 67.805 & 73.021 & 80.265 & 72.551 & 91.176 \\
\hline$q$ & 0.991 & 0.990 & 0.991 & 0.992 & 0.994 & 1.089 & 0.853 \\
\hline$Y$ & 13.150 & 13.681 & 14.347 & 15.451 & 16.984 & 15.348 & 19.246 \\
\hline C & 9.034 & 9.399 & 9.857 & 10.615 & 11.669 & 10.544 & 13.208 \\
\hline$Y_{1}$ & 1.049 & 1.049 & 1.109 & 1.211 & 1.361 & 1.155 & 0.891 \\
\hline$Y_{2}$ & 0.265 & 0.266 & 0.278 & 0.299 & 0.330 & 0.275 & 0.238 \\
\hline$Y_{3}$ & 7.206 & 7.459 & 7.866 & 8.547 & 9.511 & 7.631 & 4.599 \\
\hline$Y_{4}$ & 14.949 & 15.643 & 16.318 & 17.420 & 18.914 & 15.888 & 35.959 \\
\hline$Y_{5}$ & 17.725 & 18.414 & 19.342 & 20.885 & 23.039 & 24.172 & 20.264 \\
\hline$x_{1}$ & -0.314 & -0.368 & -0.356 & -0.335 & -0.303 & -0.267 & -1.630 \\
\hline$x_{2}$ & -2.969 & -3.116 & -3.117 & -3.113 & -3.095 & -3.055 & -6.512 \\
\hline$x_{3}$ & 0.150 & 0.145 & 0.151 & 0.160 & 0.172 & 0.148 & -1.264 \\
\hline$x_{4}$ & -0.079 & -0.073 & -0.078 & -0.086 & -0.097 & -0.078 & 0.237 \\
\hline$x_{5}$ & 0 & 0 & 0 & 0 & 0 & 0 & 0 \\
\hline$w_{1}$ & 0.264 & 0.263 & 0.255 & 0.243 & 0.228 & 0.319 & 0.193 \\
\hline$w_{2}$ & 0.438 & 0.439 & 0.422 & 0.396 & 0.363 & 0.500 & 0.339 \\
\hline$w_{3}$ & 0.583 & 0.602 & 0.583 & 0.552 & 0.512 & 0.678 & 0.320 \\
\hline$w_{4}$ & 0.346 & 0.362 & 0.346 & 0.322 & 0.291 & 0.404 & 0.169 \\
\hline$w_{5}$ & 0.191 & 0.199 & 0.191 & 0.179 & 0.163 & 0.120 & 0.279 \\
\hline$v$ & 0.037 & 0.035 & 0.037 & 0.041 & 0.048 & 0.043 & 0.056 \\
\hline 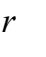 & $8.05 \%$ & $8.05 \%$ & $8.05 \%$ & $8.05 \%$ & $8.05 \%$ & $8.05 \%$ & $8.05 \%$ \\
\hline$t_{1}$ & 0.000216 & 0.000216 & 0.000229 & 0.000250 & 0.000281 & 0.000262 & 0.000158 \\
\hline 2 & 0.000046 & .000046 & 0.000049 & 0.000052 & 0.000058 & 0.000053 & 0.0000 \\
\hline
\end{tabular}

$t_{1}$ is the return on land, $t_{2}$ is the return on natural resources 


\section{Figure 1}

\section{Foreign Population as a Percentage of the Total Population}

(logarithmic scale)

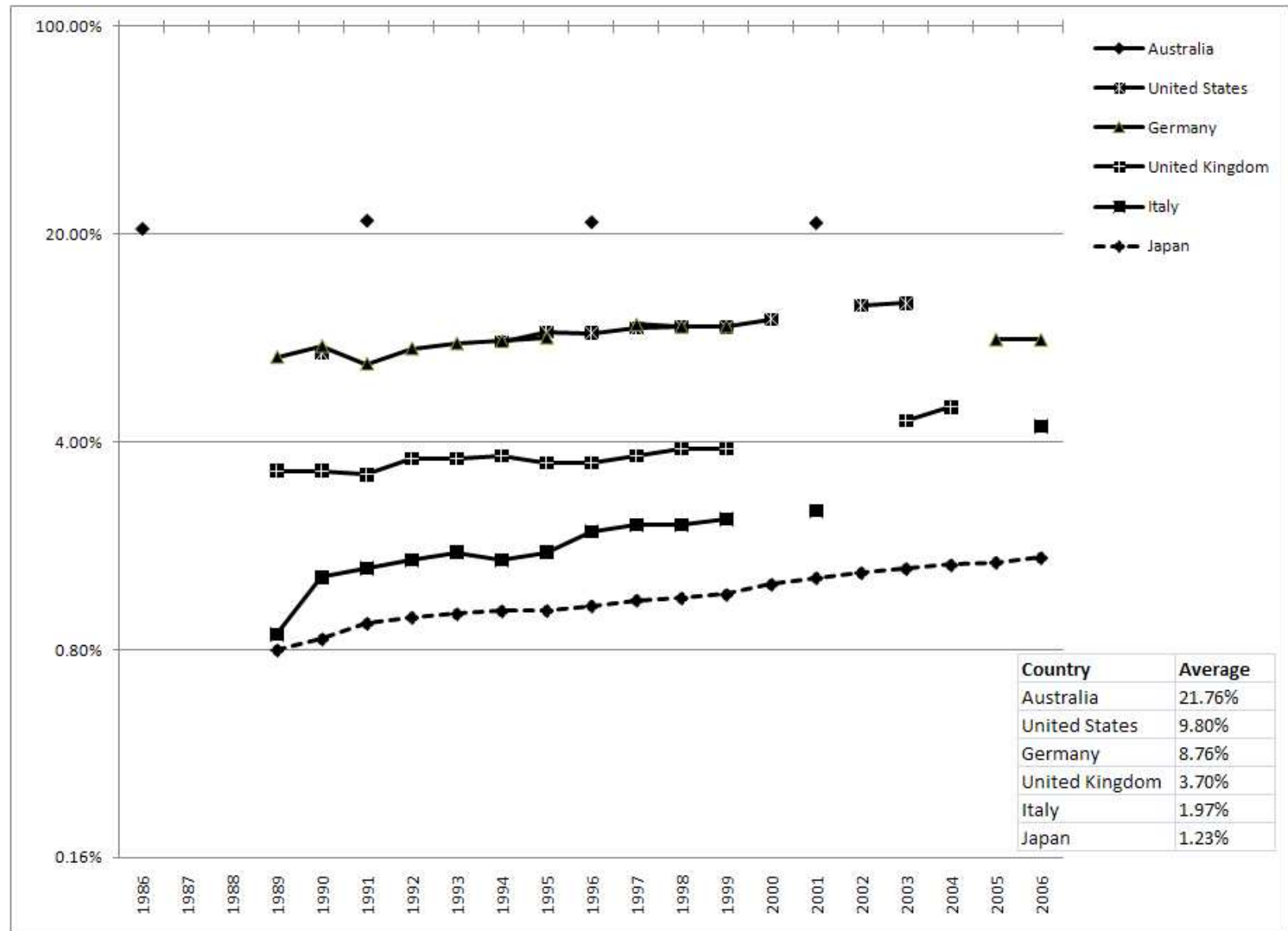

Data from the International Labour Organization - LABORSTA database 
Figure 2

Japan Migrant Population by Country of Origin 2006

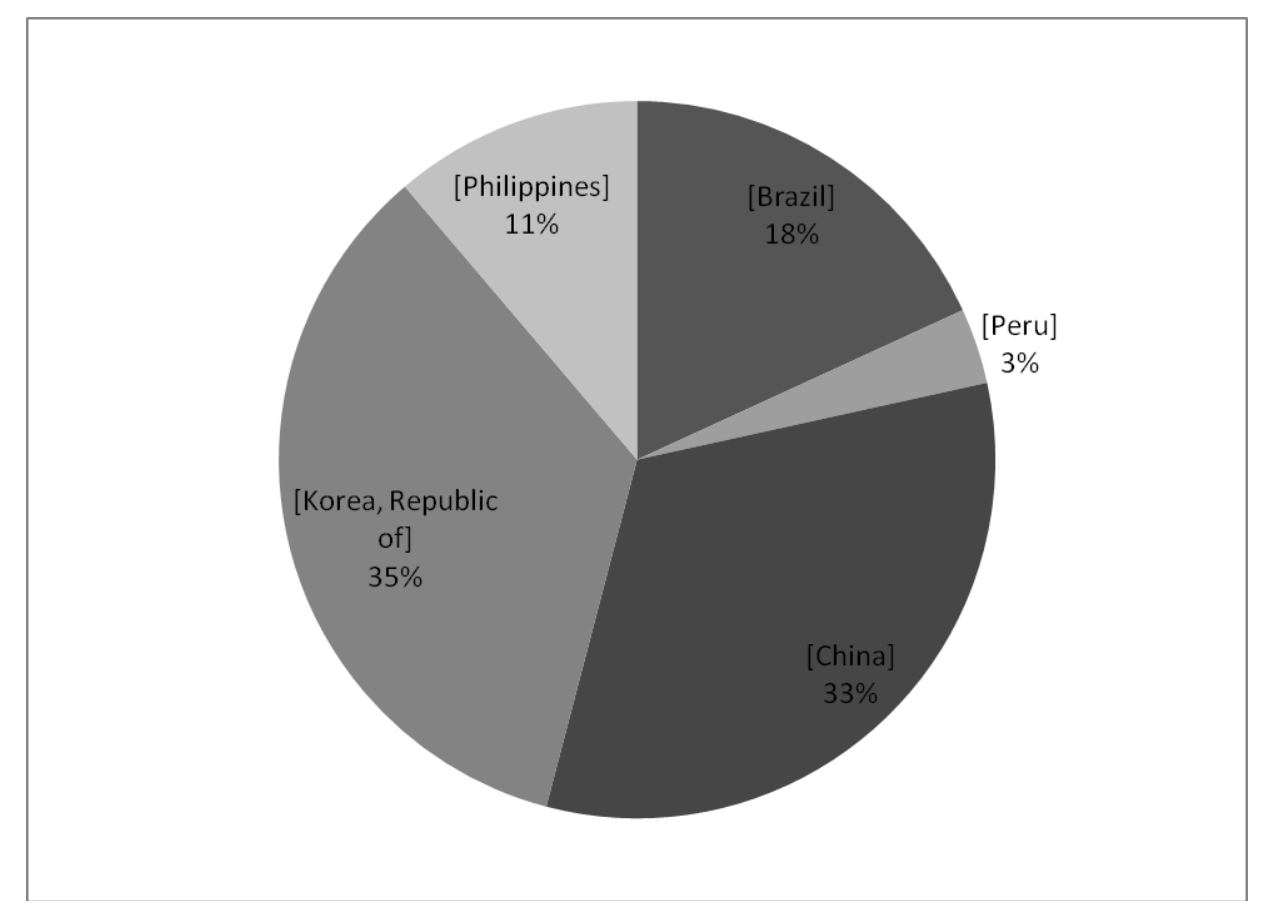


Figure 3

Transition Paths for an Increase in Unskilled Immigration Only
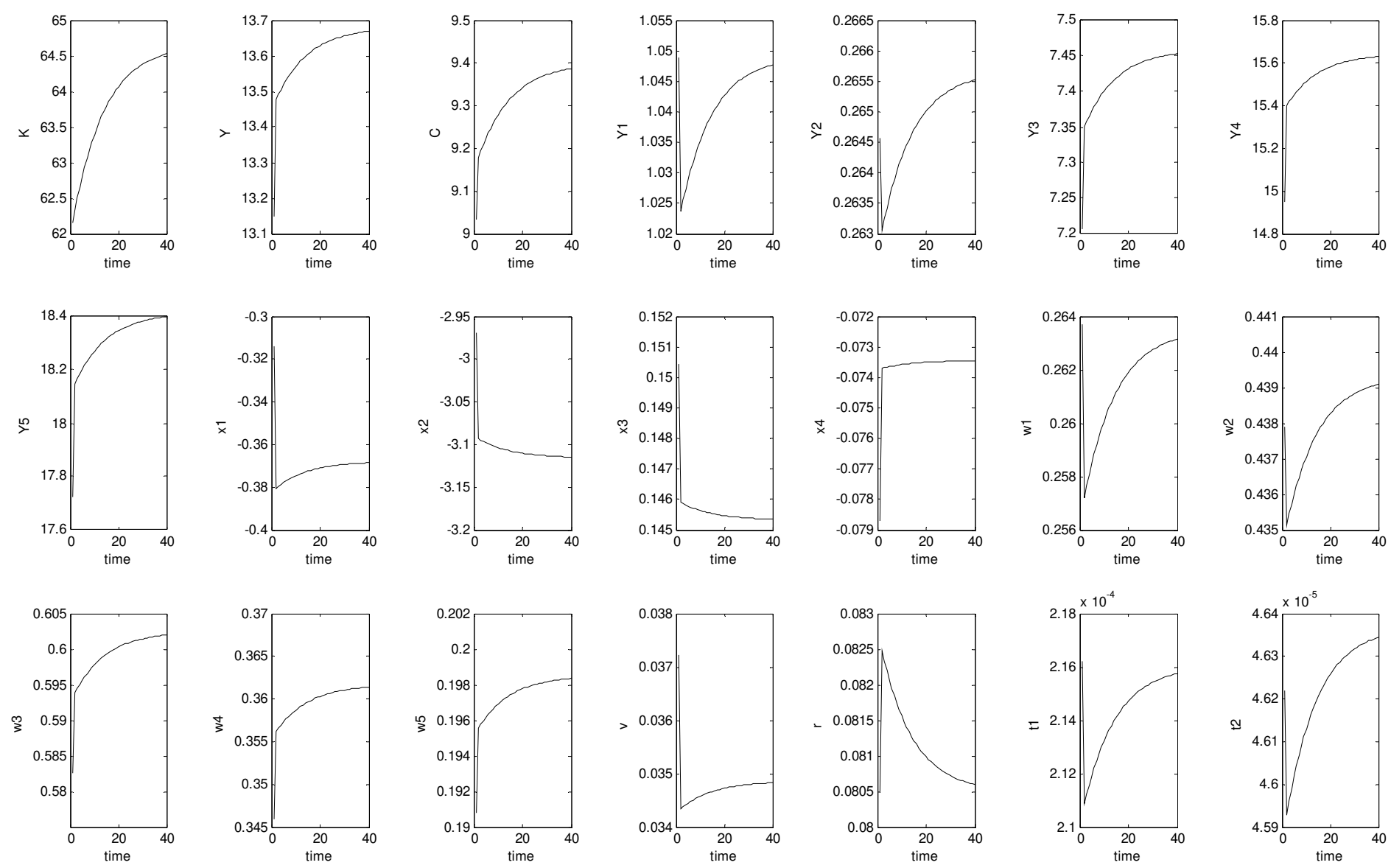
Figure 4

Transition Paths with Confidence Bands for an Increase in Unskilled Immigration Only
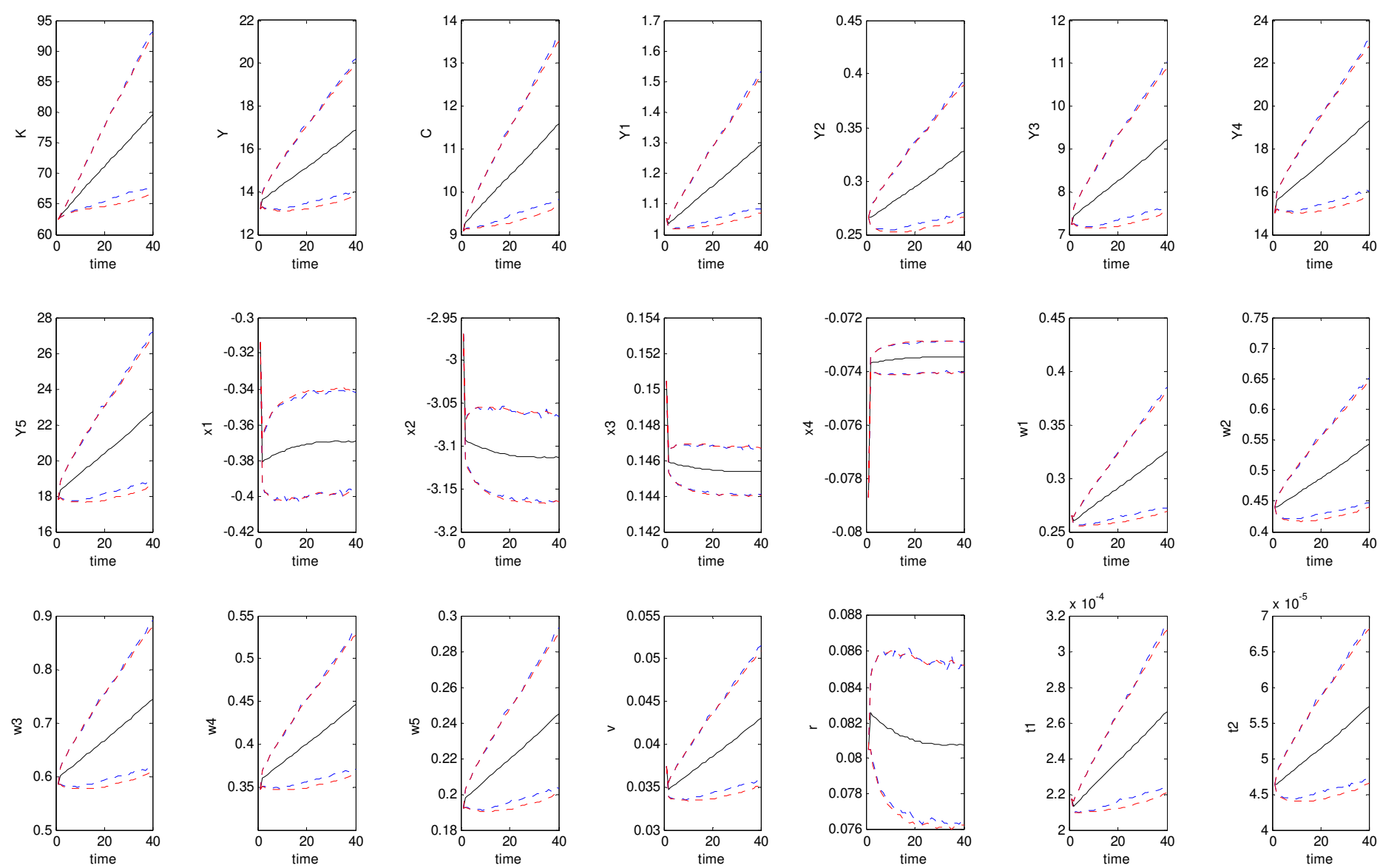


\section{Figure 5}

Transition Paths with Confidence Bands for an Proportional Increase in Skilled and Unskilled Immigration
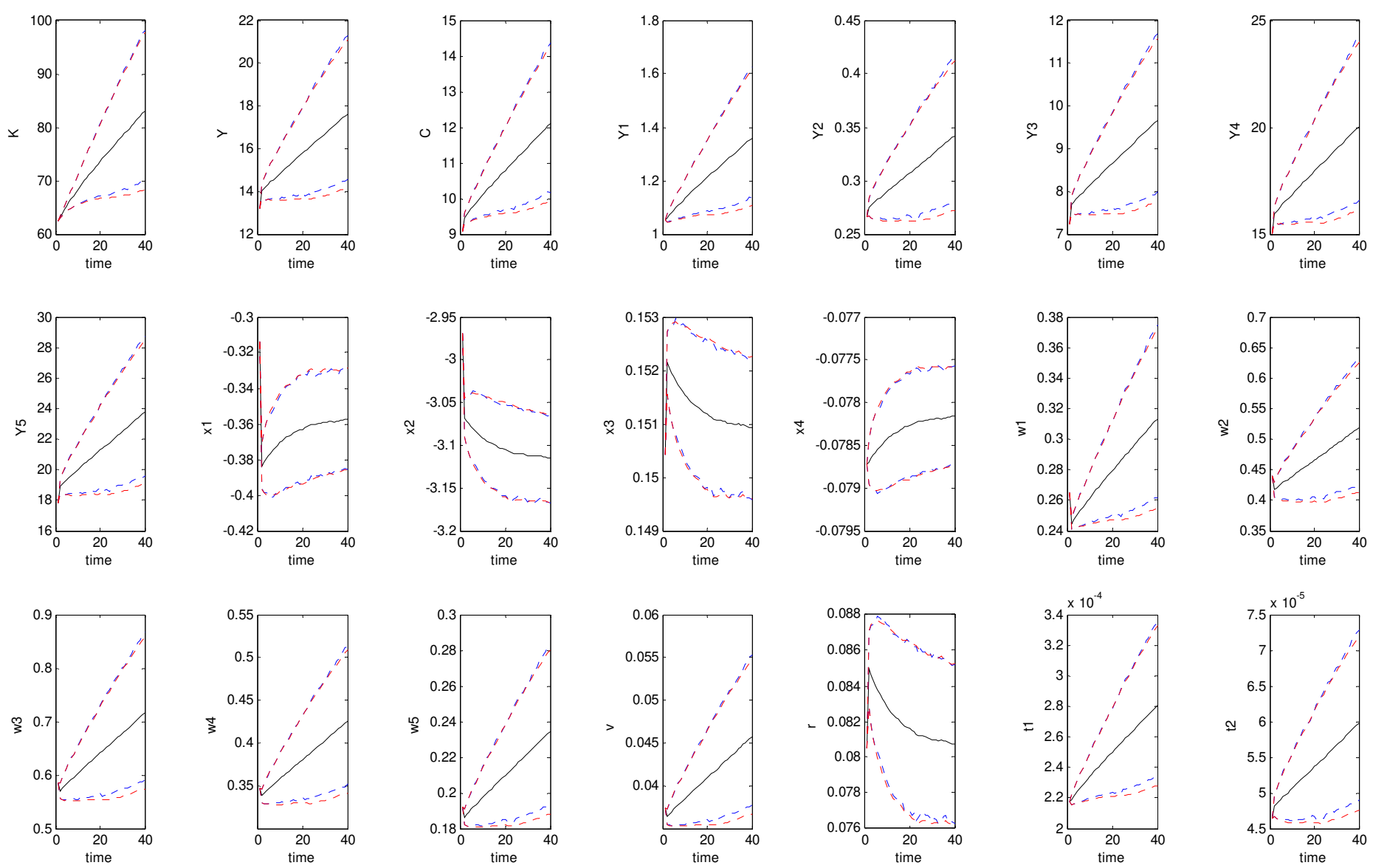


\section{Figure 6}

\section{Transition Paths with Confidence Bands for an Equal Increase in Skilled and Unskilled Immigration}
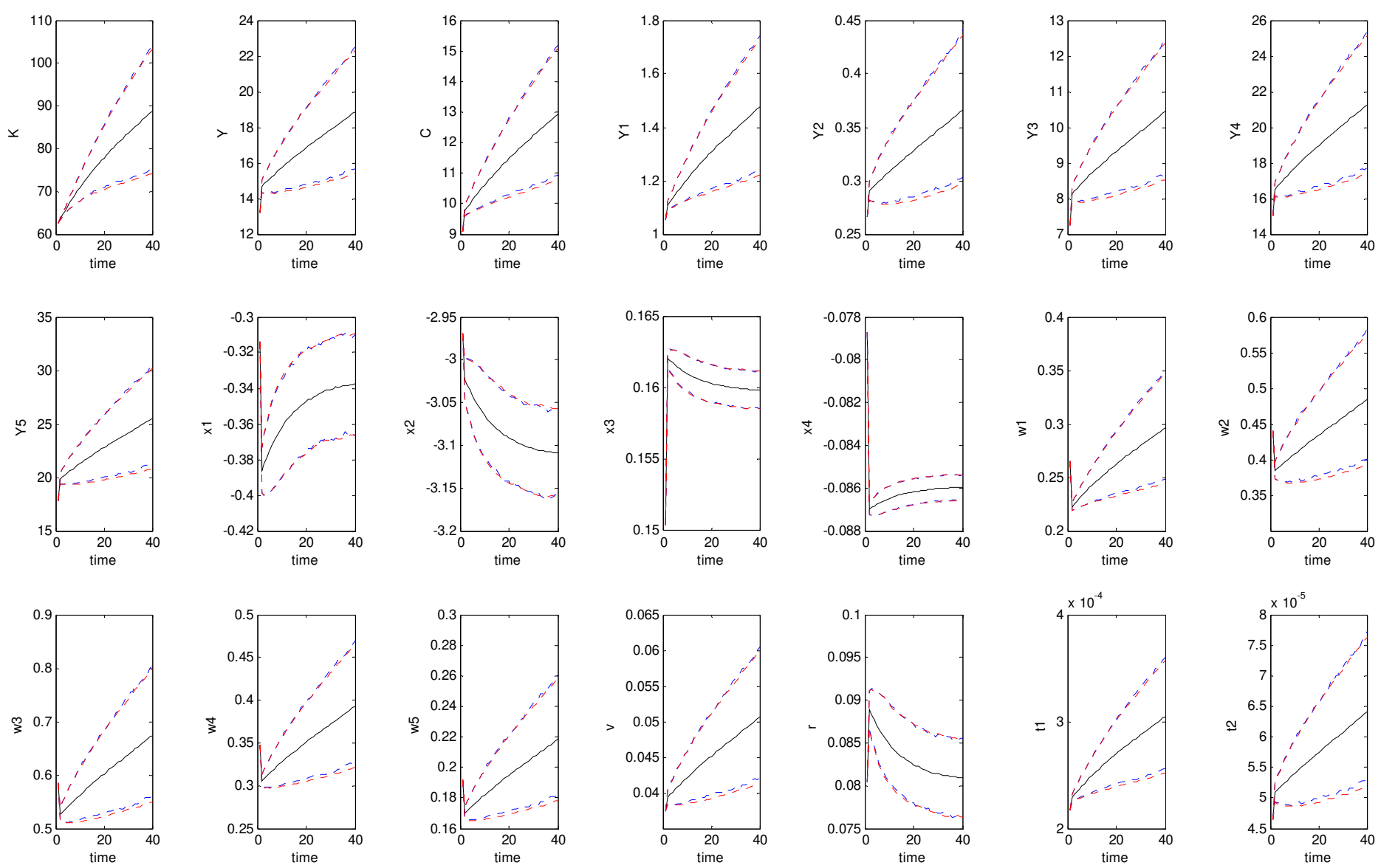
Figure 7

Transition Paths with Confidence Bands for an Increase in Skilled Immigration Only
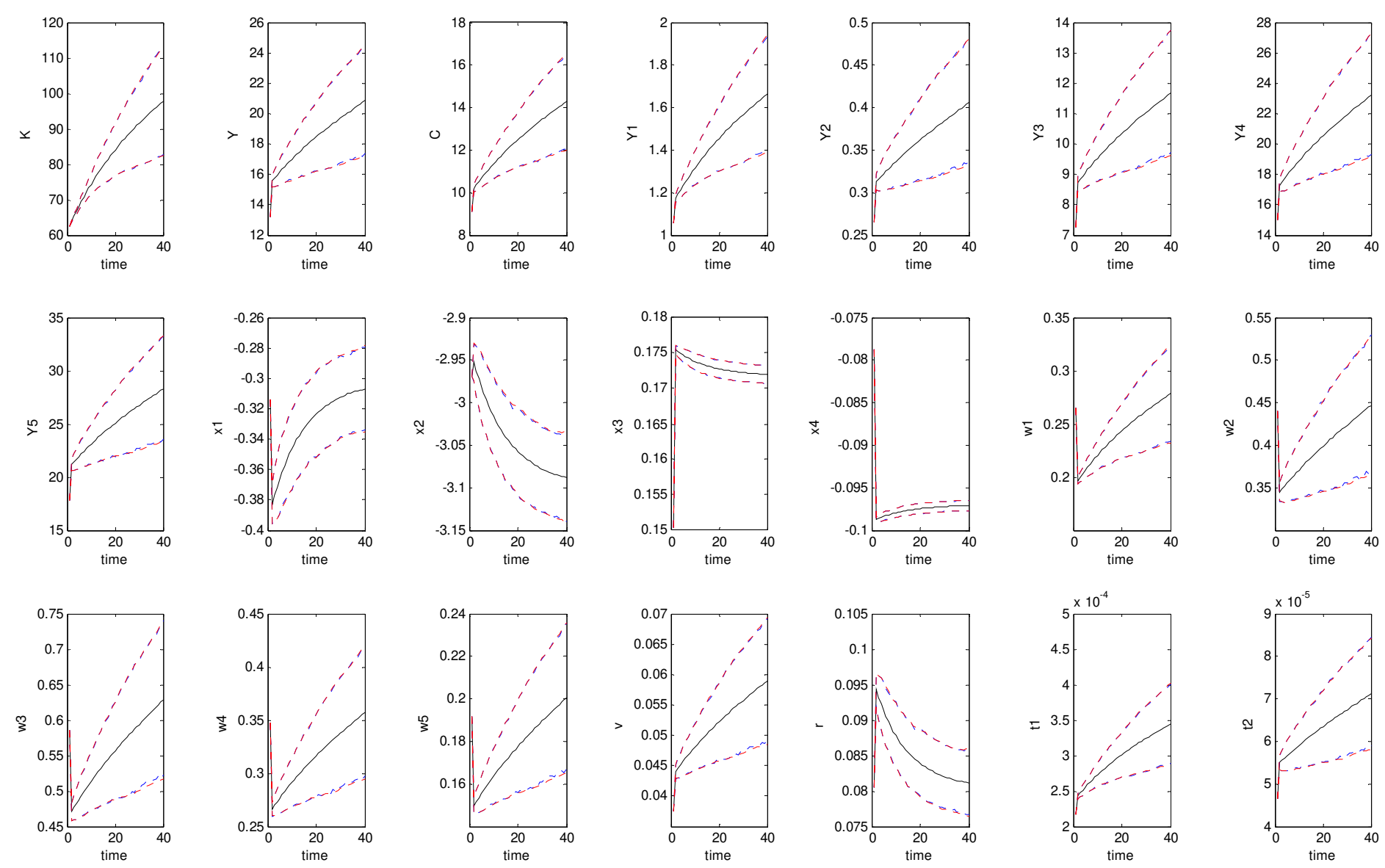
Figure 8

Transition Paths with Confidence Bands for an Increase in Skilled Immigration in Nontraded Services
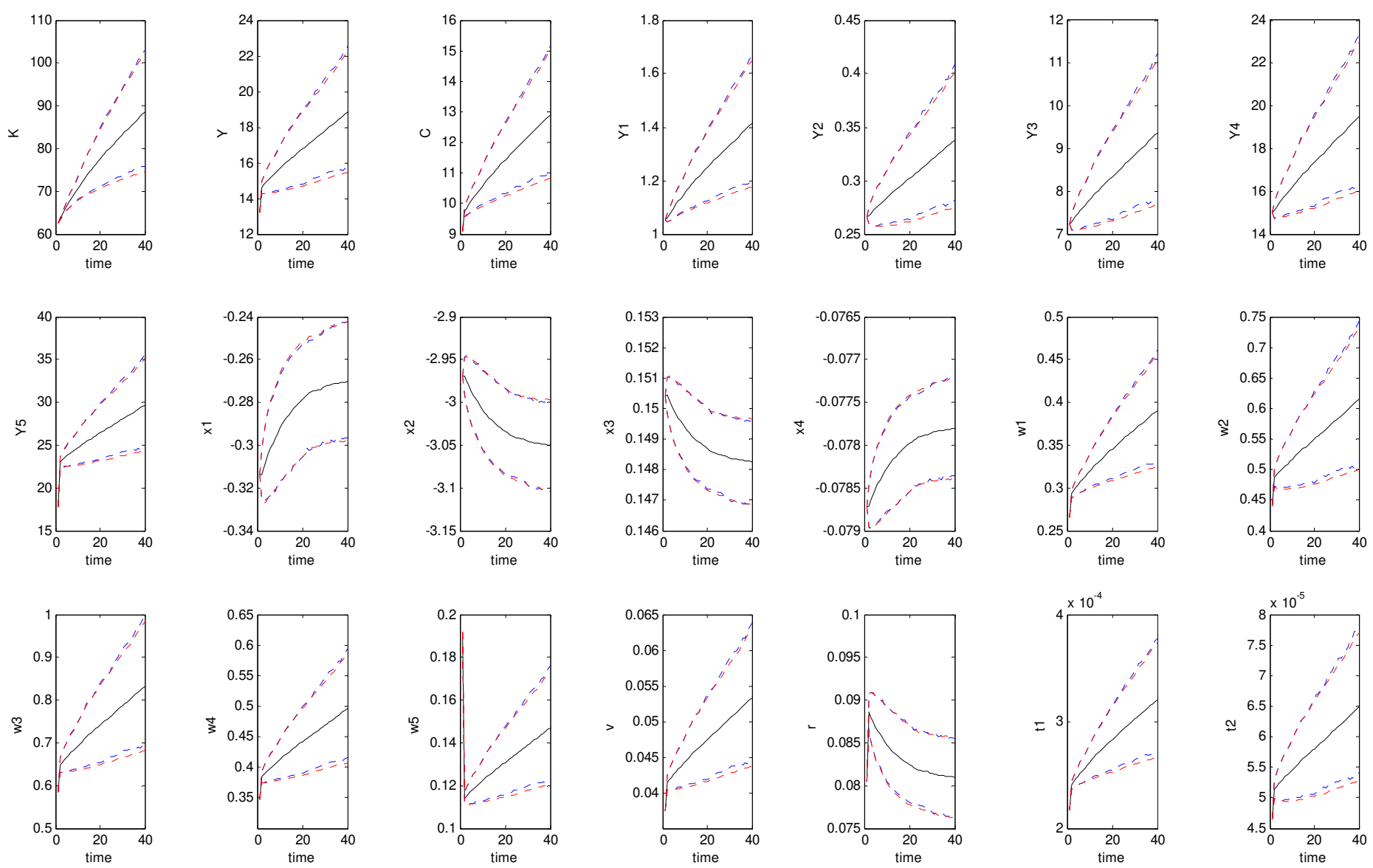


\section{Figure 9}

Transition Paths with Confidence Bands for an Increase in Skilled Immigration in Traded Services
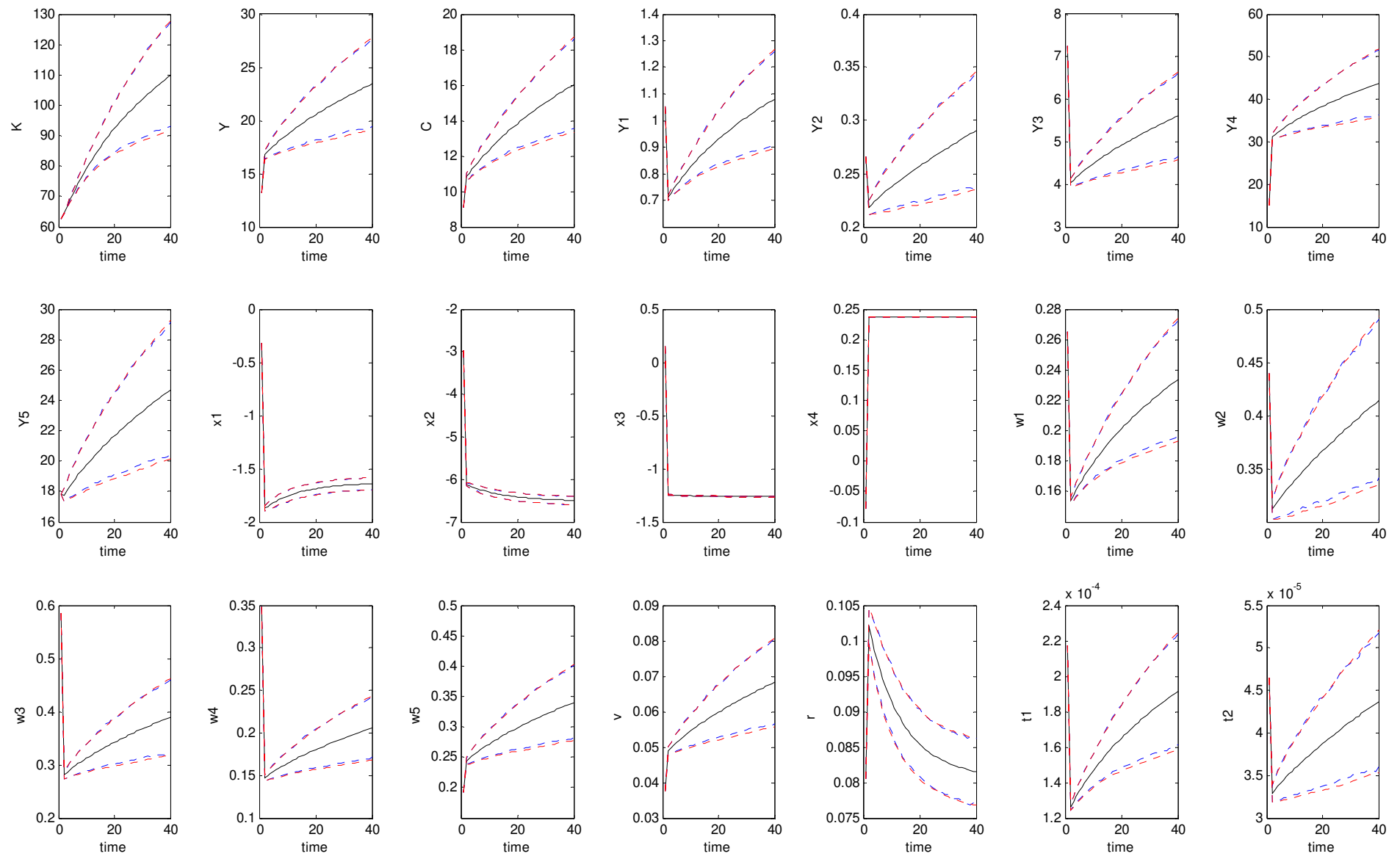


\section{References}

Choi, Yong-Yil. (2004) "The Macroeconomic Impact of Foreign Labour Influx into the Industrialized Nation State and the Complementary Policies," Applied Economics, vol. 36, pp. 1057-1063.

Christiano, Lawrence J. (2002), "Solving Dynamic Equilibrium Models by a Method of Undetermined Coefficients," Computational Economics, vol. 20, no. 1-2, pp. 21-55.

Fuess, Scott M. Jr. (2003) "Immigration Policy and Highly Skilled Workers: The Case of Japan," Contemporary Economic Policy, vol. 21 no. 2, pp. 243-57.

Goto, Junichi. (1998) “The Impact of Migrant Workers on the Japanese Economy: Trickle vs. Flood," Japan and the World Economy, vol. 10, pp. 63-83.

Kuwahara, Yasuo. (2004) "Migrant Workers in the Post-War History of Japan," Japan Labor Review, vol. 2, no. 4, pp. 25-47.

Makoto, Ogawa. (2004) “Current Issues Concerning Foreign Workers in Japan,” Japan Labor Review, vol. 2, no. 4, pp. 6-24.

Tezuka, Kazuaki (2004) "Foreign Workers in Japan: Reality and Challenges," Japan Labor Review, vol. 2, no. 4, pp. 48-71.

Uhlig, Harald. (1999) “A Toolkit for Analyzing Nonlinear Dynamic Stochastic Models Easily," in Computational Methods for the Study of Dynamic Economies, Marimon and Scott, eds., Oxford University Press, pp. 30-61. 